\title{
Effection of cordycepin on Inhibition proliferation by activating autophagy in HepG2 cell
}

\author{
LI Tianjiao ${ }^{1}$, CHENG Bijun ${ }^{1 *}$, LI Fenglin ${ }^{1}$ \\ ${ }^{1}$ College of Food Engineering, Jilin Agricultural Science and Technology University, Jilin, Jilin Province 132101, People's Republic \\ of China
}

\begin{abstract}
Cordycepin, the main active component of Cordyceps militaris, possesses a variety of biological activities. This paper investigated the inhibition of cordycepin on liver tumors. HepG2 cells were treated with cordycepin. The inhibition rates of cell proliferation was detected by MTT, LC3 protein was detected by immunofluorescence method, autophagy was observed by transmission electron microscopy, autophagy related protein was detected by Western blot. The results showed that cordycepin significantly inhibited the proliferation of HepG2 cells, and significantly increased the expression level of LC3 protein $(\mathrm{P}<0.05)$. and the autophagy increased in the cells. The Atg-related protein analysis showed that cordycepin significantly reduced the p-mTOR / $\beta$-actin ratio and $\mathrm{p} 62 / \beta$-actin ratio $(\mathrm{P}<0.01)$, and significantly increased the LC3II/LC3I ratio $(\mathrm{P}<0.01)$. The results suggested that cordycepin inhibited the proliferation by activating autophagy in HepG2 cells.
\end{abstract}

\section{Introduction}

Autophagy is a metabolism in the growth, development and pathophysiology of cells ${ }^{[1]}$. Degraded autophagic lysosomes are formed by the cell components, such as damaged organelles and proteins, which are wrapped into autophagosomes to combine with lysosomes when the stress such as hypoxia, starvation or high temperature occurs [2]. Autophagy plays an important role in anti-tumor, anti-oxidation, and anti-aging ${ }^{[3,4]}$, as well as in the treatment of diabetes, obesity, hepatic injury, and nonalcoholic fatty liver ${ }^{[5-9]}$.

So far, the mechanism of action (MOA) of autophagy in anti-tumor has not been confirmed. Some scholars suppose that autophagy eliminates damaged organelles, proteins and other components, resulting in cell growth restriction and gene instability, thus inhibiting tumor cell proliferation ${ }^{[10]}$; some scholars deem that autophagy has lethal effect on some developing tumor cells ${ }^{[11]}$; or it can prevent tumor occurrence by limiting necrosis and chronic inflammation ${ }^{[12]}$. Studies indicate a relation between autophagy and tumor. Therefore, targeting the autophagy pathway to intervene the development of tumor may be a new idea for the development of anti-tumor drugs ${ }^{[13]}$.

Cordycepin, also known as 3 -deoxyadenosine, is a nucleic acid derivative composed of adenosine and deoxypentose with carbon branched chain. Its molecular formula can be expressed as $\mathrm{C}_{10} \mathrm{H}_{13} \mathrm{~N}_{5} \mathrm{O}_{3}$ and its molecular weight is $251.25 \mathrm{Da}$. The structure of Cordycepin is shown in Fig. 1.

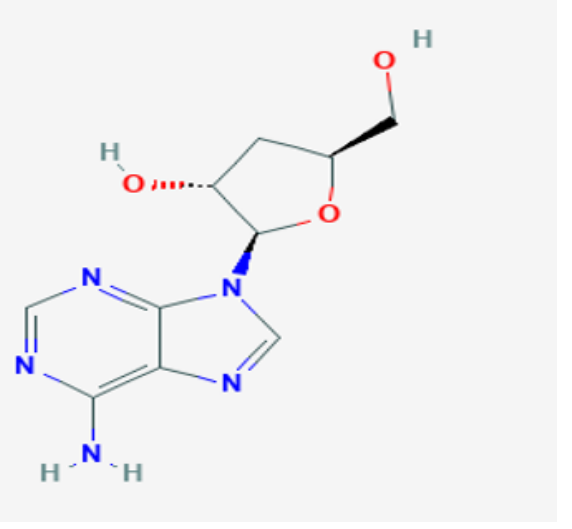

\footnotetext{
Corresponding author: ${ }^{2} 280395882 @ q q . c o m$

b549193121@qq.com
} 


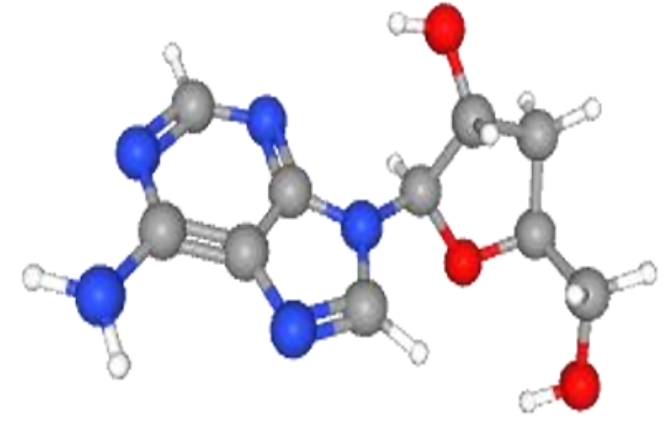

Fig.1 Two dimensional structure and three dimensional conformation of cordycepin

As a nucleoside-active component in cordyceps militaris, cordycepin boasts a variety of bioactivities, such as antibacterial, antiviral, anti-inflammatory, immune regulation, anti-tumor, etc. Studies show that cordycepin has inhibitory activity on a variety of tumors ${ }^{[15]}$. Wu Hongzhen et al ${ }^{[16]}$ divided the mice into three experimental groups: cyclophosphamide group $(20 \mathrm{mg} / \mathrm{kg} / \mathrm{d}, 9 \mathrm{~d})$, medium dose cordycepin group $(60 \mathrm{mg} / \mathrm{kg} / \mathrm{d}, 9 \mathrm{~d})$ and low-dose cordycepin group $(30 \mathrm{mg} / \mathrm{kg} / \mathrm{d}, 9 \mathrm{~d})$. The tumor inhibition rates were $55.91 \%$, $49.11 \%$ and $45.72 \%$ respectively. After the combination of cyclophosphamide and cordycepin, the tumor inhibition rate was significantly increased to $88.55 \%$. The results showed that the combination of cyclophosphamide and cordycepin can significantly improve the antitumor activity of cyclophosphamide. Thus, cordycepin can be used as an adjuvant of antitumor drugs. Nakamura et $\mathrm{al}^{[17]}$ found that the growth of mouse Lewis lung cancer cells and B16-BL6 melanoma cells was significantly inhibited because of the adenine nucleoside A3 receptor in tumor cells stimulated by the cordycepin. Huo et al ${ }^{[18]}$ found that cordycepin significantly inhibited the growth of human cervical cancer HeLa cells, human nasopharyngeal carcinoma KB cells and Ehrlich ascites tumor. The survival time of mice inoculated with Ehrlich ascites tumor was only 19 days, while that of mice treated with cordycepin can be extended to 60 days.

The results showed that cordycepin had good antitumor activity. However, the mechanism of cordycepin inhibition on tumor cells based on autophagy has not been reported. Liver tumor cells (HepG2 cells) were taken as the research object in this paper to study the MOA of cordycepin inhibiting the proliferation of tumor cells by activating autophagy. This paper aims to explore a new way to prevent and treat tumor by autophagy, so as to provide reference for the application of cordyceps militaris and the development of anti-tumor functional food.

\section{Materials \& Methods}

\subsection{Materials \& Reagents}

HepG2 cells are purchased from Shanghai Cell Bank,
Chinese Academy of Sciences.

Cordycepin from Sigma, U.S.A.; $4 \%$ paraformaldehyde from Wuhan Boster Biological Technology., LTD; dimethyl sulfoxide, glycerol, polyacrylamide from Sangon Biotech (Shanghai) Co., Ltd; Tween-20, Tris from Sigma, U.S.A.; skimmed milk powder from Bio Rad, U.S.A.; fetal bovine serum, DMEM cell culture medium from GIBCO Company, U.S.A.; glutamine from Beijing Bao Taike company; western lysate from CoWin Biosciences Co., Ltd.; PVDF membrane from Millipore, U.S.A.; protein marker from Thermo Fisher Scientific, U.S.A.; SDS protein sample buffer, SDS-PAGE dispensing kit from Shanghai Biyotime Biotechnology Co., Ltd.; PBS, double antibody (penicillin, streptomycin), $0.25 \%$ trypsin Hyclone, Trizol reagent, inventrogen, ECL, advansta, DAPI, from Shanghai Biyotime Biotechnology Co., Ltd., Anti mTOR, Anti Phosphorylated mTOR, Anti-Lc3a/B, Anti-P62 from Abcam, USA; HRP labeled goat-anti-mouse secondary antibody and HRP labeled goat-anti-rabbit secondary antibody from Beijing ZSGB-BIO Co., Ltd.; LC3 immunofluorescence staining antibody from Sigma, U.S.A.; second-fluorescence from Cell Signaling Technology, U.S.A.; and antifade mounting medium from Shanghai Biyotime Biotechnology Co., Ltd.

\subsection{Instruments \& Equipment}

ME104 Electronic Balance from Mettler Toledo, Switzerland; MCO-20AIC Carbon Dioxide Incubator from Sanyo company, Japan; HFsafe-1200TE Biosafety Cabinet from Shanghai Lishen Scientific Instrument Co., Ltd; Ti-S Fluorescence Inverted Microscope from Nikon Co., Ltd; JY-C Electrophoresis Instrument from Beijing Junyi Dongfang electrophoresis equipment Co., Ltd; DL18-DY-301 Transfer Electrophoresis Apparatus from Bio Rad Company, USA; T85X20-5A Gel Imaging Analyzer from Vilber Fusion, France; Transmission Electron Microscope from Hitachi Company, Japan; Ultrathin Section Machine from Leica Company, Germany.

\subsection{Method}

\subsubsection{To Detect Cell Proliferation with MTT Assay}

The cell concentration is adjusted to $6 \times 10^{4}$ cells $/ \mathrm{mL}$, and $100 \mu \mathrm{L}$ cell suspension (i.e. $6 \times 10^{3}$ cells/hole) is added to each hole of the 96-hole plates, and 6 multiple holes are set in each group. After PBS is added into the outer ring of the 96-hole plate, it is cultured in cell incubator for $6 \mathrm{~h}$ to get the cell adhesion. The 96-hole plate is taken out from the cell incubator, and $200 \mu \mathrm{L}$ cordycepin $(0,12.5$, $25,50,100,200 \mu \mathrm{g} / \mathrm{mL}$ ) is added into it. After 24 hours and 48 hours of culture, the cells are kept away from light. $20 \mu \mathrm{L}$ MTT assay (dissolved in PBS, with a concentration of $5 \mathrm{mg} / \mathrm{mL}$ ) is added into each hole, and then incubated in carbon dioxide incubator for $4 \mathrm{H}$. Centrifugation (1800r/min,10mins), discard the supernatant, and add $150 \mu \mathrm{L}$ dimethyl sulfoxide (DMSO) 
into each hole. After being dissolved by shaking, the absorbance is measured at $570 \mathrm{~nm}$ with an enzyme-labeled instrument, and the cell proliferation inhibition rate is calculated.

Cell Proliferation Inhibition Rate\%

Blank Group Absorbance - Administration Group Absorbance $\times 100 \%$

The half inhibitory concentration $\left(\mathrm{IC}_{50}\right)$ of cordycepin can be calculated by SPSS 19.0 software.

\subsubsection{To Detect LC3 Protein with Cell Immunofluorescence Staining}

The cell concentration is adjusted to $6 \times 10^{4}$ cells $/ \mathrm{mL} .100$ $\mu \mathrm{L}$ cell suspension (i.e. $6 \times 10^{3}$ cells/hole) is added to each hole of the 24-hole plate, with 6 multiple holes in each group. The cells are cultured in the cell incubator for 6 hours to get the cell adhesion. Then the 24-hole plate is taken out from the cell incubator. The experimental group is added with $1 \mathrm{~mL}$ of cordycepin $50 \mu \mathrm{g} / \mathrm{mL}$, $100 \mu \mathrm{g} / \mathrm{mL}$ and $200 \mu \mathrm{g} / \mathrm{mL}$ for $24 \mathrm{~h}$. The cells are fixed with $4 \%$ paraformaldehyde for 1 hour. Then, to clean it three times with PBS for 5 mins each time. Incubated with $0.5 \%$ Triton for $20 \mathrm{mins}$, cleaned with PBS three times for 5 mins each time. 1\% sheep serum is dissolved in PBS and blocked for $2 \mathrm{~h}$. Diluted primary antibody is added and cultured overnight at $4^{\circ} \mathrm{C}$. PBS is cleaned three times for 5 mins each time. Diluted fluorescent second antibody is added in the dark and incubated for 2h. PBS is cleaned three times for 5 mins each time. DAPI is added to dye the nucleus for 10 mins and then clean with PBS. The anti-fluorescence mounting media is used for mounting, which can be observed and photographed under the fluorescence microscope.

\subsubsection{To Observe Autophagy by Transmission Electron Microscope}

$5 \times 10^{5}$ cells are added into each culture dish and cultured in cell incubator for $6 \mathrm{~h}$ to get the cell adhesion. The blank group is added with complete culture medium, and the experimental group is added with $1 \mathrm{~mL}$ cordycepin $200 \mu \mathrm{g} / \mathrm{mL}$ for $24 \mathrm{~h}$ and cleaned with PBS for 3 times. After digestion, the cells are transferred to $1.5 \mathrm{~mL}$ centrifuge tubes, and $2.5 \%$ glutaraldehyde is added to each tube for $3 \mathrm{~h}$. Glutaraldehyde is removed and cleaned with PBS for $3 \times 15$ mins. $1 \%$ osmic acid is added to fix for $2 \mathrm{~h}$, and PBS is cleaned for $3 \times 15$ mins. It is dyed with $2 \%$ aqueous solution of uranium acetate for 30 mins. Then $50 \%, 70 \%$ and $90 \%$ ethanol are used to dehydrate for $15 \mathrm{mins}$, and then anhydrous ethanol is used for 3 times, $20 \mathrm{~min}$ each time. Then use acetone to dehydrate for 3 times, 20mins each time. The mixture of anhydrous acetone and embedding agent in the ratio of $1: 1$ is evenly mixed, and the cells are fully penetrated inside and outside the cells, and incubated for $2 \mathrm{~h}$. The cells are embedded with pure embedding agent, polymerized in oven, modified the boundary of cell mass, and sliced with ultrathin section machine $(80 \sim 100 \mathrm{~nm})$. Ultrathin sections are stained with $4 \%$ uranium acetate for 20 minutes and lead citrate for 5 minutes. Autophagy is observed by transmission electron microscope and photographed.

\subsubsection{To Detect Autophagy Related Proteins with Western Blot}

The cell concentration is adjusted to $5 \times 10^{5}$ cells $/ \mathrm{mL}$, and the cells are seeded in a 6-hole plate for culture. The experimental groups are treated with $50 \mu \mathrm{g} / \mathrm{mL}, 100$ $\mu \mathrm{g} / \mathrm{mL}$ and $200 \mu \mathrm{g} / \mathrm{mL}$ cordycepin respectively. After centrifugation $(1300 \mathrm{r} / \mathrm{min}, 15 \mathrm{mins})$, the supernatant is aspirated, the cell lysate is added, and the ice is lysed for 30mins. Centrifugation (20000r/min, $5 \mathrm{mins})$ is performed at $4{ }^{\circ} \mathrm{C}$. The supernatant is the protein lysate. BCA protein quantitative kit is used to determine the cell protein concentration in the lysate. The amount of sample and protein is $10 \mu \mathrm{L}$ and $40 \mu \mathrm{g}$ respectively. The mixture of $5 \times \mathrm{SDS}$ buffer and lysate is heated at $100^{\circ} \mathrm{C}$ for 8 mins. $8 \%$ after polyacrylamide -SDS gel electrophoresis, electricity is transferred to PVDF film and placed on ice and 3\% BSA containing TBS-Tween 20 sealing solution is used to oscillate and block $4 \mathrm{~h}$. The diluted primary antibody is added and incubated overnight at $4^{\circ} \mathrm{C}$. The diluted secondary antibody is added and incubated in $37^{\circ} \mathrm{C}$ shaking table for $2 \mathrm{~h}$. TBST buffer solution is used to clean the membrane three times for 15 mins each time. The prepared ECL luminescent solution is dripped onto PVDF film and developed in ECL luminescent instrument.

\subsection{Data Processing}

The test results can be shown by $(\mathrm{x} \pm \mathrm{SD})$ and three independent trials are repeated. One-way analysis of variance (ANOVA) in SPSS statistics 19.0 is used for significance analysis. In the Western blot test, ImageJ software is used to analyze the protein. The software Graphpad Prism 5.0 is used for the drawing.

\section{Results \& Analysis}

\subsection{Inhibitory Effect of Cordycepin on Proliferation of HepG2 Cells}

In order to investigate the effects of cordycepin and palmitic acid on the activity of HepG2 cells, different concentrations of cordycepin $0,12.5,25,50,100,200$ $\mu \mathrm{g} / \mathrm{mL}$ are used to treat HepG2 cells for 24 hours and 48 hours. As shown in Fig.2, the inhibition rate of cordycepin on cell proliferation increased with the increase of mass concentration in a dose-dependent manner. The inhibition rate of cell proliferation is $0.83 \%$, $3.64 \%, 9.24 \%, 25.67 \%$ and $38.14 \%$ at $12.5,25,50,100$ and $200 \mu \mathrm{g} / \mathrm{mL}$ of cordycepin, respectively; the inhibition rate of cordycepin on cell proliferation increased with the extension of treatment time, with a time-dependent manner. The inhibition rates of cordycepin on cell proliferation are $2.18 \%, 8.29 \%$, 
$27.61 \%, 57.74 \%$ and $76.62 \%$, respectively. The IC50 of cordycepin is $86 \mu \mathrm{g} / \mathrm{mL}$.

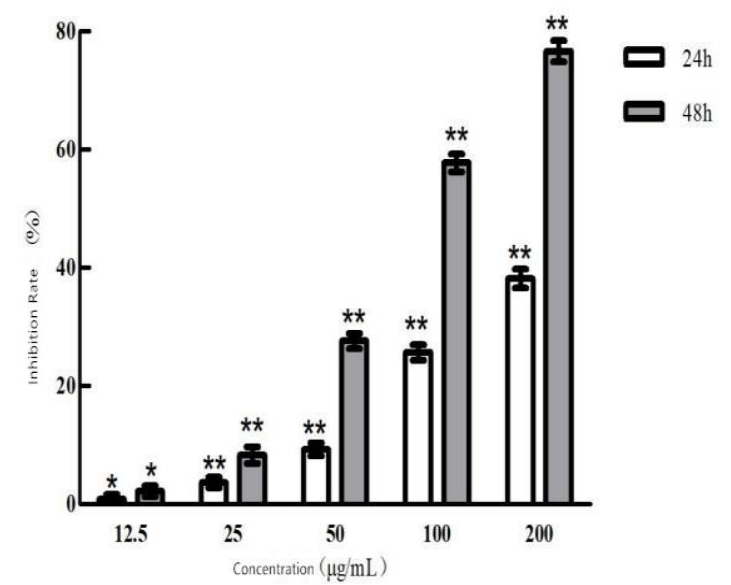

* *** are used to indicate the significant difference between the two groups $(\mathrm{p}<0.05, \mathrm{p}<0.01)$

Fig.2 Inhibitory effects of cordycepin on the proliferation of HepG2 cells

\subsection{To Detect the Effect of Cordycepin on Autophagy of HepG2 Cells with Cell Immunofluorescence Staining}

LC3 protein is detected by immunofluorescence method, and the level of autophagy is determined by fluorescence microscope. Blue fluorescence represents nucleus and green fluorescence represents LC3. As shown in Figure 3, the expression of LC3 protein in the blank group is low; after pretreatment with $0,50,100$ and $200 \mu \mathrm{g} / \mathrm{mL}$ cordycepin for $24 \mathrm{~h}$, the dot green fluorescence in the cells is gradually enhanced, and after the pretreatment with $200 \mu \mathrm{g} / \mathrm{mL}$ cordycepin, the fluorescence intensity is extremely significantly higher than that of the blank group. The results showed that $200 \mu \mathrm{g} / \mathrm{mL}$ cordycepin significantly increased the expression level of LC3 protein.
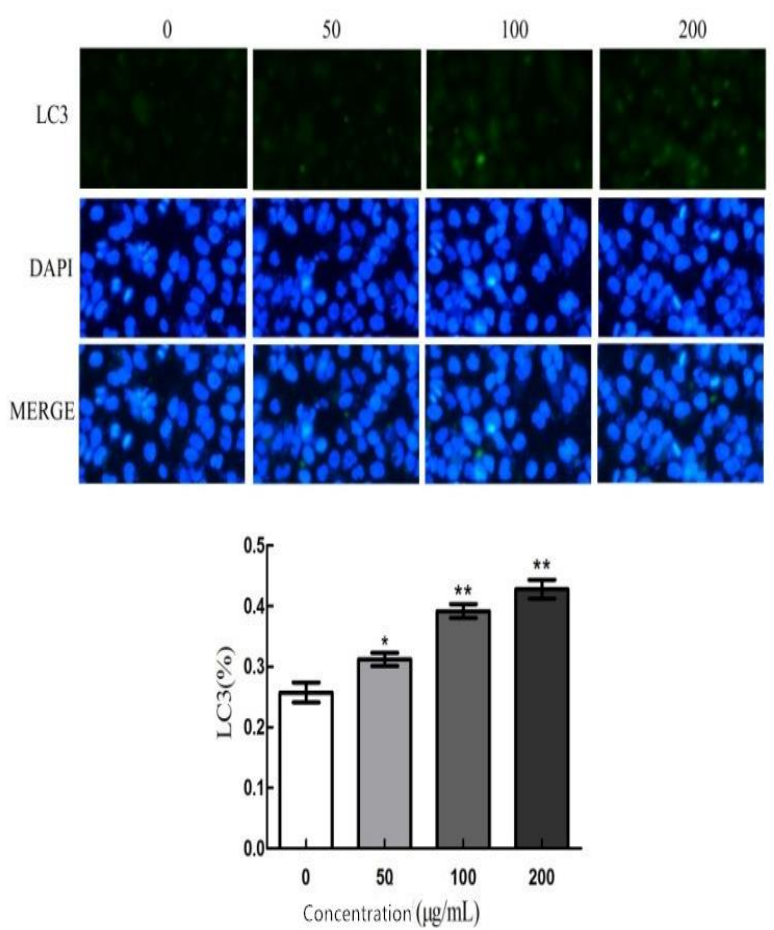

* **are used to indicate the significant difference between the two groups $(\mathrm{P}<0.05, \mathrm{P}<0.01)$

Fig.3 Effect of cordycepin on autophagy of HepG 2 cells detected by immunofluorescence staining

\subsection{To Detect the Effect of Cordycepin on Autophagy of Hepg2 Cells with Transmission Electron Microscopy}

Transmission electron microscopy is a benchmark for autophagy detection among all detection methods. The ultrastructural changes in HepG2 cells, like autophagosomes with a double membrane structure, were observed by transmission electron microscopy in the test, as shown by the red arrow in Fig. 4. Compared with the blank group, the number of autophagosomes is increased after the cells are pretreated with $200 \mu \mathrm{g} / \mathrm{mL}$ cordycepin for $24 \mathrm{~h}$, which is shown in Fig.4. The effect of cordycepin promoting autophagy formation in HepG2 cells can be visually shown with transmission electron microscopy. 


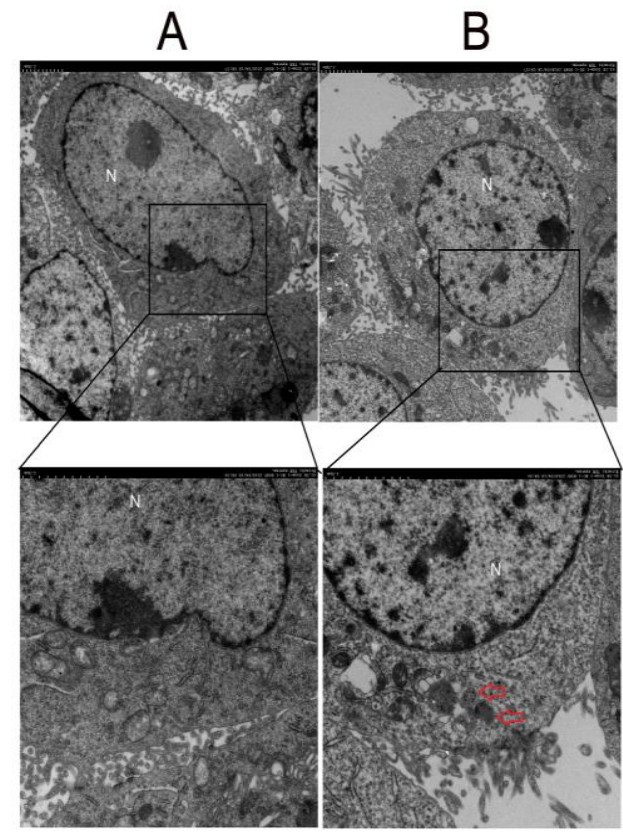

A was blank group, B was experimental group; autophagy was marked with red arrow; nucleus was labeled with $\mathrm{N}$

Fig.4 Effect of Cordycepin on autophagy of HepG2 cells detected by TEM

\subsection{To Detect the Effect of Cordycepin on Autophagy Related Proteins in Hepg2 Cells with Western Blot}

The cells are pretreated with $0,50,100$ and $200 \mu \mathrm{g} / \mathrm{mL}$ cordycepin for $24 \mathrm{~h}$, and autophagy related proteins are detected. As shown in Figure 5, compared with the blank group, the relative expression of $\mathrm{P}-\mathrm{mTOR} / \beta$-actin is significantly decreased $(\mathrm{P}<0.01)$, the ratio of LC3II/LC3I is significantly increased $(\mathrm{P}<0.01)$, and the relative expression of p62 is significantly decreased $(\mathrm{P}<$ $0.01)$. The results show that. With the increase of the concentration of cordycepin, the expression level of autophagy related proteins changed significantly. Cordycepin may induce autophagy formation and autophagy lysosome dissolution by affecting the expression of autophagy related proteins, thus activating autophagy.

\section{A}

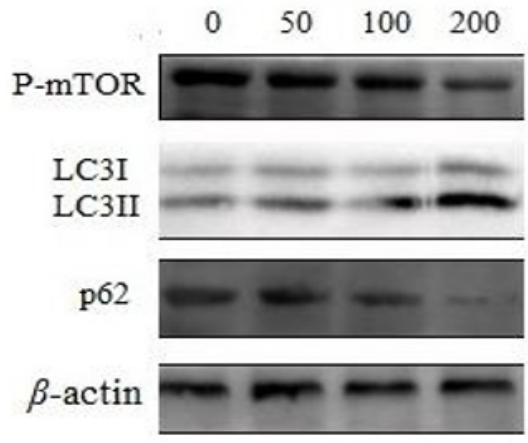

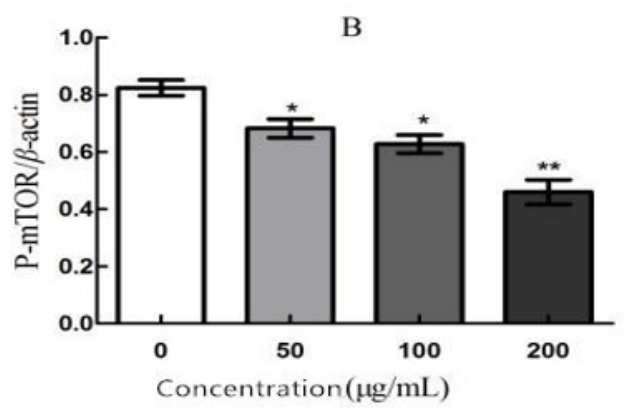
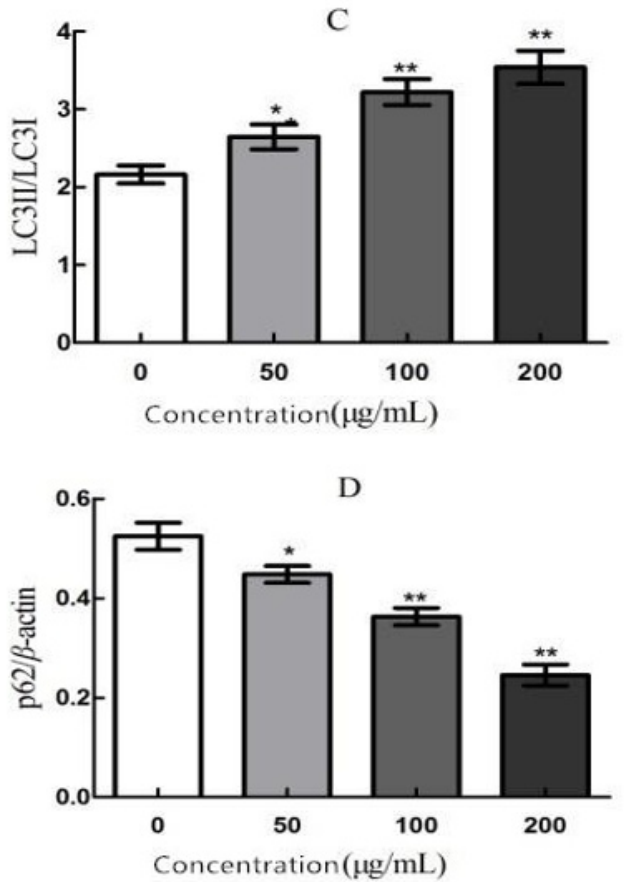

A. Results of autophagy-related protein expression; B. The relative expression of p-mTOR protein was detected; C. LC3II / LC3I ratio; D. Relative expression of p62 protein

Fig.5 Effect of cordycepin on the expression of autophagy-associated proteins in HepG2 cells

\section{Discussion}

This paper found that cordycepin could significantly promote LC3 protein expression by detecting LC3 protein with immunofluorescence method. The ultrastructure of HepG2 cells is observed by transmission electron microscope. It is found that autophagy of bilayer vesicles increased significantly after cordycepin intervention. LC3 is an essential protein in the process of autophagy extension and maturation. There are two subtypes of LC3: LC3I and LC3II. It is known that the level of LC3II is associated with the number of autophagosomes. In the late stage of autophagy, LC3 participates in the membrane fusion, extension and closure of autophagy ${ }^{[19]}$. The autophagy activity can be determined by the content of $\mathrm{LC} 3$ or the ratio of LC3II/LC3I [20].

Western blot analysis showed that the ratio of LC3II / LC3I can significantly increase $(\mathrm{P}<0.01)$, the relative expression of $\mathrm{p} 62 / \beta$-actin can be significantly decreased $(\mathrm{P}<0.01)$, and the relative expression of 
$\mathrm{P}$-mTOR/ $\beta$-actin can be significantly decreased $(\mathrm{P}<$ 0.01). p62 is a multifunctional protein of autophagy receptor of ubiquitinated protein aggregation. p62 and LC3 proteins are classified as selective autophagy receptors. p62 can interact with LC3 and degrade with substrate. Autophagy usually occurs at sites of selective substrate aggregation ${ }^{[21-22]}$. In the absence of substrates, most autophagic receptors, including p62, are continuously degraded by autophagy. Therefore, autophagy activity can be reflected by p62 protein content ${ }^{[23-24]}$. In addition, autophagy-related proteins are regulated by mammalian target of rapamycin (mTOR). Studies have shown that nutritional responsive mTOR can inhibit autophagy. Starvation and dephosphorylation of mTOR can promote autophagy activation, catabolism and cell survival. The mTOR plays an important role in the regulation of cell proliferation and autophagy ${ }^{[25]}$. The results showed that after the intervention of cordycepin, the expression of autophagy-related proteins changed significantly, which can activate autophagy and inhibit the proliferation of HepG2 cells.

Li Fang [26] found that gecko crude peptide can significantly increase LC3II protein and inhibit the proliferation of human hepatoma HepG2 cells by activating autophagy. Yu Yanxia ${ }^{[27]}$ found that rapamycin can inhibit proliferation of a variety of malignant tumor cells by inducing autophagy. Guo Yaya ${ }^{[28]}$ found that alkyl resorcinol in wheat bran can effectively inhibit the growth of HepG2 cells, and it is speculated that its mechanism may be through promoting autophagy or inducing apoptosis. Liu Lan ${ }^{[29]}$ observed the autophagy bodies by MDC staining and detected the expression of autophagy protein by western blot. The results showed that resveratrol can induce autophagy of HepG2 cells and promote apoptosis, thus inhibiting cell proliferation. Gao Xiaofei ${ }^{[30]}$ found that TIP-6 (a new imidazolopyridine derivative) may cause autophagic death by activating the $\mathrm{NF}-\kappa \mathrm{B}$ expression, thus inhibiting the proliferation of HepG2 cells.

Autophagy is a highly conserved mechanism in almost all cells. Under physiological conditions, autophagy is at a low level. When the body is in a state of stress, such as lack of nutrition, autophagy can decompose protein and fat, providing raw materials and energy for metabolism and regulating biological functions ${ }^{[31]}$. The occurrence of autophagy is too low to provide the material and energy needed for cell survival; excessive activation of autophagy will destroy too many proteins and organelles, leading to cell death, which is called type 2 programmed cell death ${ }^{[32]}$. In addition, studies found that NF- $\kappa \mathrm{B}$ signaling pathway can also affect autophagy and apoptosis ${ }^{[33]}$. Cell deaths are in various forms, of which and the mechanism is complex. Autophagy, apoptosis and NF- $\mathrm{KB}$ signaling pathways are different from each other. Thus, the relations among them need further study ${ }^{[34]}$.

In conclusion, cell proliferation inhibition can be detected with MTT assay. LC3 Protein expression can be detected with cell immunofluorescence method. Autophagy can be observed with transmission electron microscope. The expression of autophagy related proteins can be detected with western blot. The results indicate that cordycepin may inhibit the proliferation of HepG2 cells by inducing autophagy, and the specific mechanism needs to be further studied. However, regulating autophagy may be a potential strategy to interfere with the growth of hepatocellular carcinoma, which provides a reference for the application and development of cordyceps militaris.

\section{Acknowledgements}

This study was supported in part by Fund project of Jilin Agricultural Science and Technology University (No. 20190549), and in part by Fund project of Jilin Agricultural Science and Technology University (No. 20190277)

\section{References}

1.Martinet W, Agostinis P, Vanhoecke B, et al. Autophagy in disease: a double-edged sword with therapeutic potential[J]. Clinical science, 2009, 116(9): 697-712.

2.Rabinowitz J D, White E. Autophagy and metabolism[J]. Science, 2010, 330(6009): 1344-1348.

3.Czaja M J, Ding W X, Donohue T M, Jr., et al. Functions of autophagy in normal and diseased liver[J]. Autophagy, 2013, 9(8): 1131-1358.

4.Mehrpour M, Esclatine A, Beau I, et al. Autophagy in health and disease. 1. Regulation and significance of autophagy: an overview[J]. American journal of physiology Cell physiology, 2010, 298(4): C776-785.

5.Parzych K R, Klionsky D J. An Overview of Autophagy: Morphology, Mechanism, and Regulation[J]. Antioxidants \& redox signaling, 2014, 20(3): 460-473.

6.Stefan, Ryter, Ja, et al. Molecular regulation of autophagy and its implications for metabolic diseases [J]. Current Opinion in Clinical Nutrition \& Metabolic Care, 2014, 17(4): 329-337.

7.Gracia-Sancho J, Guixé-Muntet S. The many-faced role of autophagy in liver diseases[J]. J Hepatol, 2018, 68(3): 593-594.

8.Liu Z, Zhu P, Zhang L, et al. Autophagy inhibition attenuates the induction of anti-inflammatory effect of catalpol in liver fibrosis[J]. Biomedicine \& Pharmacotherapy, 2018, 103(4):1262-1271.

9.Qu X, Gao H, Tao L, et al. Autophagy inhibition-enhanced assembly of the NLRP3 inflammasome is associated with cisplatin-induced acute injury to the liver and kidneys in rats[J]. J Biochem Mol Toxic, 2018, 26 (7):581-586.

10.Mowers E E, Sharifi M N, Macleod K F. Functions of autophagy in the tumor microenvironment and 
cancer metastasis[J]. Febs Journal, 2018, 285(10): 1751-1766.

11.Che J, Liang B, Zhang Y, et al. Kaempferol alleviates ox-LDL-induced apoptosis by up-regulation of autophagy via inhibiting $\mathrm{PI} 3 \mathrm{~K} / \mathrm{Akt} / \mathrm{mTOR}$ pathway in human endothelial cells[J]. Cardiovascular Pathology, 2017, 31(3): 57-62.

12.Malicdan M C, Noguchi S, Nonaka I, et al. Lysosomal myopathies: An excessive build-up in autophagosomes is too much to handle $[\mathrm{J}]$. Neuromuscul Disord, 2008, 18(7): 520-529.

13.Li Y J, Lei Y H, Yao N, et al. Autophagy and multidrug resistance in cancer[J]. cancer, 2017, 36(8): 342-351.

14.Bernard A, Klionsky D J. Autophagosome formation: tracing the source[J]. Developmental cell, 2013, 25(2): 116-117.

15.Li T, Wen L, Cheng B. Cordycepin alleviates hepatic lipid accumulation by inducing protective autophagy via PKA/mTOR pathway[J]. Biochemical and biophysical research communications, 2019, 516(3): 632-638.

16.Wu Hong Zhen, Jiang Wei, Ma De'en. Study on the Inhibitory Effect of Cordycepin on S (180) Tumor in Mouse [J]. Lishizhen Medicine and Materia Medica Research, 2000, 35 (10): 873-874.

17.Nakamura K, Yoshikawa N, Yu Y, et al. Antitumor effect of Cordycepin ( $3^{\prime}$-deoxyadenosine) on mouse melanoma and lung carcinoma cells involves adenosine A3 receptor stimulation[J]. Anticancer research, 2006, 26(1A): 43-47.

18.Huo X, Liu C, Bai X, et al. Aqueous extract of Cordyceps sinensis potentiates the antitumor effect of DDP and attenuates therapy-associated toxicity in non-small cell lung cancer via $\mathrm{I} \kappa \mathrm{B}$ a /NF $\kappa$ B and AKT/MMP2/MMP9 pathways[J]. RSC Advances, 2017, 7(60): 37743-37754.

19.FENG Y C, HE D, YAO Z Y, et al. The machinery of macroautophagy[J]. Cell Res, 2014, 24(1): 24-41.

20.Tobe K, Suzuki R, Aoyama M, et al. Increased expression of the sterol regulatory element-binding protein-1 gene in insulin receptor substrate-2(-/-) mouse liver[J]. The Journal of biological chemistry, 2001, 276(42): 38337-38340.

21.ROGOV V, DOTSCH V, JOHANSEN T, et al. Interactions between Autophagy Receptors and Ubiquitin-like Proteins Form the Molecular Basis for Selective Autophagy[J]. Mol Cell, 2014, 53(2): 167-178.

22.FRACCHIOLLA D, SAWA-MAKARSKA J, ZENS B, et al. Mechanism of cargo-directed Atg8 conjugation during selective autophagy[J]. Elife, $2016,5$.
23. Kabeya Y, Mizushima, et al. LC3, a mammalian homologue of yeast Apg8p, is localized in autophagosome membranes after processing $[\mathrm{J}]$. 2000, 19(21): 5720-5728.

24. Tanabe F, Yone K, Kawabata N, et al. Accumulation of p62 in degenerated spinal cord under chronic mechanical compression[J]. Autophagy, 2011, 7(12): 1462-1471.

25.Jung C H, Ro S H, Cao J, et al. mTOR regulation of autophagy[J]. FEBS letters, 2010, 584(7): 1287-1295.

26.Li Fang, Xu Ping, Wang Yun, et al. Effects of Gecko Crude Peptide on Proliferation and Autophagy-Related Protein Expression of Hepatoma HepG2 Cells [J]. Chinese Journal of Clinical Pharmacology, 2019, 35 (16): 1791-1793.

27.Yu Yanxia, Gu Zhenlun, Qin Zhenghong, et al. Autophagy Activation and the Effect of Antitumor Drugs [J]. Chinese Pharmacological Bulletin, 2006, 22 (002): 137-141.

28.Guo Yaya, Yang Xiaoming, Li Yueying. Alkylresorcinol in Wheat Bran Induces Autophagy and Apoptosis in HepG2 cells [J]. Food Science, 2020, 41 (05): 102-107.

29.Liu Lan, Zhang Zhimin, Fu Hongxing, et al. Effects of Resveratrol on Proliferation and Apoptosis of HepG2 Cells through Autophagy [J]. Journal of Oncology, 2019, 25 (02): 51-56.

30.Gao Xiaofei, Hai Jun, Du Yuping, et al. Tip-6 Inhibits Proliferation of Cultured HepG2 Cells and Normal Hepatocytes by Inducing Autophagy $[\mathrm{J}]$. Chinese Journal of Cellular and Molecular Immunology, 2009, 25 (10): 883-886.

31.Lazaratos S, Kashimura H,Nakahara A, et al. Gastric ulcer induced by submucosal injection of ET -1: role of potent vasoconstriction and in-traluminal acid[J]. Am J Phvsiol, 1993, 265:G491-498.

32.Ren Ning, Wang Shiming, Dong Xiushan, et al. Effects of Autophagy on Proliferation and Cell Cycle of HepG2 Cells [J]. China Modern Medicine, 2012, 19 (11): 8-9.

33.Bobin Mi, Junqing Wang, Yi Liu,et al. Icariin Activates Autophagy via Down-Regulation of the NF- $\kappa$ B Signaling-Mediated Apoptosis in Chondrocytes[J]. Frontiers in Pharmacology, 2018 , 09: 605 .

34.Wang Lisheng, Li Yingxue, Zhu Huiming, et al. Effects of Bifidobacterium DNA on PKC and $\mathrm{NF}-\kappa \mathrm{B}$ in Mouse Macrophages [J]. Chinese Journal of Cellular and Molecular Immunology, 2007, 23 (1): 11-13. 